\title{
RESISTÊNCIA DE MELOEIRO A BEMISIA TABACI BIÓTIPO B ( ${ }^{1}$ )
}

\author{
SÉRGIO ALEXANDRE MOTTOLA PEREIRA COELHO $\left({ }^{2,4}\right)$; ANDRÉ LUIZ LOURENÇÃO $\left({ }^{2 *}\right)$; \\ ARLETE MARCHI TAVARES DE MELO $\left({ }^{2}\right)$; ELIANA APARECIDA SCHAMMASS $\left({ }^{3}\right)$
}

\begin{abstract}
RESUMO
Em âmbito mundial, a mosca-branca Bemisia tabaci (Genn.) biótipo B é praga-chave em diversas culturas. $\mathrm{O}$ uso de resistência varietal se destaca entre os métodos de controle, sendo considerado o método ideal. O objetivo do presente trabalho foi avaliar, em casa de vegetação, a resistência de 32 cultivares de meloeiro em relação a essa mosca-branca. Para atratividade, em 'Neve' observou-se o menor número de adultos na face abaxial das folhas $\left(0,6\right.$ adulto $\left./ 10 \mathrm{~cm}^{2}\right)$, enquanto 'Nilo' foi a mais preferida $(5,6$ adultos/ $10 \mathrm{~cm}^{2}$ ). A oviposição foi avaliada em testes com e sem chance de escolha; em ambos, 'Neve' proporcionou o menor número de ovos, contrastando com 'Nilo', a cultivar com a maior média. A colonização da mosca-branca durante o ciclo das plantas foi avaliada por meio de uma escala de notas variando de 0 (ausência de colonização) até 6 (folha totalmente colonizada); 'Neve' destacou-se por sua reduzida colonização, sendo as mais altas médias obtidas em 'Imperial', 'Jangada', 'Vereda', 'Deneb' e 'Nilo'. Na duração do ciclo ovo-adulto da mosca-branca, que variou de 24,0 ('Neve') a 25,4 dias ('Jangada'), as cultivares não diferiram entre si. Quanto à emergência de adultos, as menores médias foram induzidas por Vereda' $(68,2 \%)$ e 'Nilo' $(69,3 \%)$, indicando a possível ocorrência de resistência do tipo antibiose nessas duas cultivares, enquanto as maiores médias ocorreram em 'Imperial' (90,9\%) e 'Deneb' $(89,6 \%)$. Considerando-se os parâmetros avaliados, infere-se que 'Neve' é a cultivar mais resistente a B. tabaci biótipo B, podendo ser indicada para plantio em regiões onde essa praga ocorra de forma acentuada ou para uso em programas de melhoramento.
\end{abstract}

Palavras-chave: Insecta, não-preferência, resistência de plantas a insetos, Cucumis melo.

\section{ABSTRACT \\ RESISTANCE OF MELON TO BEMISIA TABACI BIOTYPE B}

Silverleaf whitefly B. tabaci biotype B is an important worldwide pest of many crops. Use of resistant cultivars is considered the ideal method of control. In this research, 32 cultivars of melon were evaluated under greenhouse conditions reganding resistance to silverleaf whitefly. As to adult attractiveness, 'Neve' had the lowest number of adults on the abaxial surfaces of leaves $\left(0.6\right.$ adult $\left./ 10 \mathrm{~cm}^{2}\right)$ while 'Nilo' was the more attractive $\left(5.6\right.$ adults $\left./ 10 \mathrm{~cm}^{2}\right)$. The oviposition preference was evaluated in free-choice and no-choice tests. In both, 'Neve' was less oviposited and 'Nilo' had the highest number of eggs. The silverleaf whitefly colonization was evaluated by scores varying from 0 (no colonization) to 6 (leaves completely colonized). While 'Neve' showed the lowest level of colonization, high levels were observed in 'Imperial', 'Jangada', 'Vereda', 'Deneb' and 'Nilo'. The B. tabaci biotype B egg-adult cycle varied from 24.0 ('Neve') to 25.4 days ('Jangada'), without any significant differences among the genotypes. The lowest rates of adult

( $\left.{ }^{1}\right)$ Recebido para publicação em 9 de abril de 2008 e aceito em 8 de julho de 2009.

$\left({ }^{2}\right)$ Instituto Agronômico (IAC), Caixa Postal 28, 13012-970 Campinas (SP). E-mail: andre@iac.sp.gov.br (*) Autor correspondente.

$\left({ }^{3}\right)$ Instituto de Zootecnia (IZ), Rua Heitor Penteado, 56, Centro, Nova Odessa (SP).

$\left({ }^{4}\right)$ Bolsista FAPESP. 
emergence were observed in 'Vereda' (68.2\%) and 'Nilo' (69.3\%), suggesting that antibiosis is the mechanism of resistance, while 'Imperial' (90.9\%) and 'Deneb' (89.6\%) presented the highest rates. Considering the evaluated characteristics, 'Neve' is the most resistant cultivar to silverleaf whitefly and should be tested in highly infested areas. Additionally, it might be a valuable source of resistance for breeding programs.

Key words: Insecta, silverleaf whitefly, nonpreference, host plant resistance, Cucumis melo

\section{INTRODUÇÃO}

A fruta do meloeiro (Cucumis melo L.), segundo dados do Ministério da Agricultura, Pecuária e Abastecimento do Brasil, em 2007, foi a segunda mais exportada em valores (128 milhões de dólares) e volume (204 mil t) (MAPA, 2008), com aumento de $45,30 \%$ nas vendas em relação ao ano anterior.

Atualmente, Bemisia tabaci (Genn.) biótipo B (Hemiptera: Aleyrodidae) é considerada a pragachave para a cultura do meloeiro em todas as regiões produtoras do Brasil (FERNANDEs et al., 2000), devido ao dano direto e principalmente pela ação vetora do vírus causador do "amarelão-do-meloeiro". AzEvEDo e Bleicher (2003) também assinalaram sua importância como praga, destacando que, nos últimos anos, essa mosca-branca tem se tornado a praga mais importante da cultura do melão em diversos Estados brasileiros. RiLEY e PALUMBO (1995) observaram que o aumento no número total de imaturos de moscabranca em cultivos de meloeiro corresponde à queda significativa no peso e número de caixas colhidas além da qualidade final do produto, devido ao decréscimo no tamanho do fruto e no teor de sólidos solúveis totais e aumento da ocorrência de fumagina.

De acordo com SimMONS e McCREIGHT (1996), aplicações foliares de inseticidas têm sido pouco eficientes, principalmente pelo fato de as ninfas se localizarem na face abaxial das folhas do meloeiro e as plantas serem de crescimento rasteiro, dificultando as pulverizações. DenHOLm et al. (1996) e HOROWITZ e IsHAAYA (1996) salientaram a inconveniência do uso continuado de determinado inseticida para o controle de $B$. tabaci biótipo $B$, pois este inseto possui capacidade de desenvolver resistência a todas as classes de inseticidas.

Como alternativa ao uso intenso de agrotóxicos para seu controle, deve ser estimulado cada vez mais o estudo da resistência varietal desta cultura a B. tabaci biótipo B (VILlas BôAs et al., 2004), método de controle que preconiza a obtenção de material resistente a pragas e doenças (LARA, 1991).

Assim, este trabalho foi realizado com objetivo de avaliar a resistência de cultivares de meloeiro em relação a $B$. tabaci biótipo $B$, determinando-se a atratividade para adultos, a preferência para oviposição, o desenvolvimento ovo-adulto e a colonização do inseto.

\section{MATERIAL E MÉTODOS}

Toda a experimentação foi realizada em condições de casa de vegetação, em Campinas (SP), no período de 2006 a 2008.

\section{Criação-estoque de B. tabaci biótipo B}

Para a criação da mosca-branca, foi utilizada uma pequena casa de vegetação $(3 \times 5 \mathrm{~m})$, constituída por base de alvenaria ( $1 \mathrm{~m}$ de altura), laterais de tela antiafídeo e teto de vidro, com bancadas. Adultos de mosca-branca foram coletados em lavoura de tomateiro no município de Paulínia, Estado de São Paulo, sendo transferidos para plantas de soja e de couve livres de insetos, dispostas nessa casa de vegetação. Após a colonização das plantas e emergência de adultos, estes

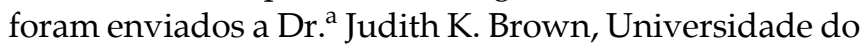
Arizona, EUA, que os identificou como B. tabaci biótipo B. Periodicamente, são colocados vasos com aboboreiras na criação para expressarem o prateamento das folhas, anomalia fisiológica causada pela alimentação de ninfas desse biótipo (Brown et al., 1995), a fim de confirmar a identidade do inseto. Sempre que senescentes, plantas de soja e couve são trocadas por outras mais novas a fim de prover condições adequadas ao inseto.

\section{Seleção das cultivares de meloeiro utilizadas}

Dentre as empresas fornecedoras de sementes de melão do país, foram selecionadas as principais cultivares de interesse comercial. Procurou-se selecionar, nesse processo, as cultivares com resistência a diferentes agentes fitopatogênicos, visando obter germoplasma com alta variabilidade genética (Tabela 1).

\section{Atratividade para adultos e preferência para oviposição de B. tabaci biótipo B em teste com chance de escolha}

Para cultivo das plantas, foram utilizados vasos com capacidade para três litros, preenchidos com mistura de terra, areia e composto orgânico, adubados e corrigido o $\mathrm{pH}$ de acordo com as recomendações da cultura (RAIJ et al., 1997), conforme resultados de análise desse solo. 
Tabela 1. Médias $( \pm \mathrm{EP})$ de atratividade para adultos e preferência para oviposição de $B$. tabaci biótipo B, na face abaxial defolhas em 32 cultivares de meloeiro, avaliadas em teste com chance de escolha, em casa de vegetação. Campinas (SP), 2006

\begin{tabular}{|c|c|c|c|c|c|c|c|}
\hline \multirow[b]{2}{*}{ Cultivar } & \multirow[b]{2}{*}{ Procedência } & \multicolumn{4}{|c|}{ Número de adultos $/ 10 \mathrm{~cm}^{2}\left({ }^{1,2}\right)$} & \multirow[b]{2}{*}{ Média } & \multirow{2}{*}{$\begin{array}{c}\text { Número de } \\
\text { ovos } / 10 \mathrm{~cm}^{2}\left({ }^{1,2}\right)\end{array}$} \\
\hline & & $\begin{array}{c}\text { 1. }{ }^{\text {a }} \text { avaliação } \\
\text { (24 horas) }\end{array}$ & $\begin{array}{c}\text { 2. }{ }^{\text {a }} \text { avaliação } \\
\text { (48 horas) }\end{array}$ & $\begin{array}{c}\text { 3. }{ }^{a} \text { avaliação } \\
\text { (72 horas) }\end{array}$ & $\begin{array}{c}\text { 4. }{ }^{\text {a }} \text { avaliação } \\
\text { (96 horas) }\end{array}$ & & \\
\hline Neve & Feltrin & 0,7 & 1,0 & $0,5 \mathrm{~b}$ & 0,2 & $0,6 \mathrm{~b}$ & $8,5 \pm 0,33 \mathrm{~d}$ \\
\hline Deneb & Syngenta & 0,5 & 0,7 & $0,7 \mathrm{~b}$ & 1,4 & $0,8 \mathrm{ab}$ & $32,6 \pm 1,42 \mathrm{bcd}$ \\
\hline Jangada & Sakata & 1,4 & 0,7 & $0,8 \mathrm{~b}$ & 1,0 & $1,0 \mathrm{ab}$ & $22,3 \pm 0,80 \mathrm{~cd}$ \\
\hline Vereda & Syngenta & 1,0 & 1,9 & $1,0 \mathrm{~b}$ & 1,2 & $1,3 \mathrm{ab}$ & $32,0 \pm 1,53 \mathrm{bcd}$ \\
\hline Hales B. J. & Feltrin & 0,5 & 1,0 & $1,2 \mathrm{~b}$ & 2,4 & $1,3 \mathrm{ab}$ & $51,9 \pm 2,02 \mathrm{abcd}$ \\
\hline Louis & Takii & 1,4 & 1,4 & $1,4 \mathrm{~b}$ & 1,4 & $1,4 \mathrm{aab}$ & $48,3 \pm 2,49 \mathrm{abcd}$ \\
\hline Merak & Syngenta & 0,8 & 1,6 & $2,3 \mathrm{ab}$ & 1,8 & $1,6 a a b$ & $66,8 \pm 2,17 \mathrm{abcd}$ \\
\hline Gaúcho & Isla & 2,2 & 1,8 & $1,5 \mathrm{~b}$ & 1,2 & $1,7 \mathrm{ab}$ & $59,6 \pm 3,77 \mathrm{abcd}$ \\
\hline Sweet M. & Feltrin & 0,6 & 1,5 & $2,0 \mathrm{ab}$ & 3,0 & $1,8 \mathrm{ab}$ & $34,4 \pm 1,64 \mathrm{bcd}$ \\
\hline Eldorado 300 & Isla & 1,0 & 2,0 & $2,9 \mathrm{ab}$ & 2,4 & $2,1 \mathrm{ab}$ & $86,5 \pm 2,27 \mathrm{abcd}$ \\
\hline MP 1000 & Syngenta & 1,7 & 2,3 & $2,4 a b$ & 2,1 & $2,1 \mathrm{ab}$ & $62,4 \pm 1,83 \mathrm{abcd}$ \\
\hline Metis & Syngenta & 0,6 & 1,5 & $2,5 \mathrm{ab}$ & 4,1 & $2,1 \mathrm{ab}$ & $49,8 \pm 1,67$ abcd \\
\hline Gold Mine & Semminis & 1,8 & 2,0 & $2,4 \mathrm{ab}$ & 2,6 & $2,2 \mathrm{ab}$ & $85,6 \pm 3,57 \mathrm{abcd}$ \\
\hline Juicy Sun & Feltrin & 1,1 & 3,0 & $1,5 \mathrm{~b}$ & 3,5 & $2,3 \mathrm{ab}$ & $108,1 \pm 6,69 \mathrm{abcd}$ \\
\hline Hy Mark & Semminis & 1,1 & 2,1 & $3,6 \mathrm{ab}$ & 3,0 & $2,4 \mathrm{ab}$ & $114,3 \pm 4,51 \mathrm{abcd}$ \\
\hline Mehari & Syngenta & 1,1 & 1,9 & $2,2 \mathrm{ab}$ & 4,7 & $2,5 \mathrm{ab}$ & $85,0 \pm 2,91 \mathrm{abcd}$ \\
\hline Frevo & Sakata & 1,4 & 2,6 & $3,6 a b$ & 2,6 & $2,5 \mathrm{ab}$ & $108,0 \pm 2,17 \mathrm{abcd}$ \\
\hline Canarian $\mathrm{K}$. & Isla & 1,8 & 2,5 & $3,3 a b$ & 2,9 & $2,6 a b$ & $110,1 \pm 4,38 \mathrm{abcd}$ \\
\hline Sunrise & Takii & 1,4 & 2,3 & $3,3 \mathrm{ab}$ & 3,8 & $2,7 \mathrm{ab}$ & $114,0 \pm 2,79 \mathrm{abcd}$ \\
\hline Rochedo & Semminis & 1,5 & 2,6 & $3,3 \mathrm{ab}$ & 3,6 & $2,7 \mathrm{ab}$ & $83,4 \pm 3,21 \mathrm{abcd}$ \\
\hline Gold 264 & Semminis & 0,9 & 1,7 & $2,2 \mathrm{ab}$ & 6,4 & $2,8 \mathrm{ab}$ & $97,8 \pm 5,92 \mathrm{abcd}$ \\
\hline Vera Cruz & Syngenta & 2,0 & 2,3 & $3,5 \mathrm{ab}$ & 3,5 & $2,8 \mathrm{ab}$ & $81,9 \pm 1,38$ abcd \\
\hline Sancho & Syngenta & 1,8 & 2,5 & $4,0 \mathrm{ab}$ & 3,6 & $3,0 \mathrm{ab}$ & $123,6 \pm 3,29 a b c$ \\
\hline Bônus II & Takii & 1,9 & 2,8 & $4,3 \mathrm{ab}$ & 3,0 & $3,0 \mathrm{ab}$ & $100,6 \pm 3,08 \mathrm{abcd}$ \\
\hline AF646 & Sakata & 1,4 & 2,3 & $5,0 \mathrm{ab}$ & 3,6 & $3,1 \mathrm{ab}$ & $85,5 \pm 3,49$ abcd \\
\hline Imperial & Isla & 1,3 & 2,8 & $3,4 a b$ & 4,7 & $3,1 \mathrm{ab}$ & $216,8 \pm 5,45 a b$ \\
\hline Sedna & Syngenta & 1,7 & 2,7 & $3,9 a b$ & 4,4 & $3,2 \mathrm{ab}$ & $143,4 \pm 3,2 \mathrm{abc}$ \\
\hline RML 5006 & Syngenta & 1,3 & 2,7 & $5,6 a b$ & 3,4 & $3,3 \mathrm{ab}$ & $98,1 \pm 3,62 \mathrm{abcd}$ \\
\hline Tuareg & Syngenta & 2,4 & 3,2 & $5,1 \mathrm{ab}$ & 4,6 & $3,8 \mathrm{ab}$ & $161,3 \pm 3,53 a b c$ \\
\hline Galax & Takii & 1,6 & 3,3 & $5,3 \mathrm{ab}$ & 5,6 & $3,9 \mathrm{ab}$ & $172,3 \pm 6,59 \mathrm{abc}$ \\
\hline Raptor & Syngenta & 1,8 & 3,9 & $5,1 \mathrm{ab}$ & 5,5 & $4,1 \mathrm{ab}$ & $197,7 \pm 4,78 \mathrm{ab}$ \\
\hline Nilo & Sakata & 2,1 & 6,2 & 8,4 a & 5,9 & 5,6 a & $271,5 \pm 8,74 \mathrm{a}$ \\
\hline$F(G)$ & - & n.s. & n.s. & $* *$ & n.s. & $* *$ & $* *$ \\
\hline CV (\%) & - & - & - & 81,29 & - & 44,06 & 40,00 \\
\hline
\end{tabular}

( $\left.{ }^{1}\right)$ Médias seguidas pela mesma letra na coluna não diferem significativamente entre si pelo teste de Tukey $(p<0,05)$.

$\left({ }^{2}\right)(p<0,01)$. ns = não significativo

Dados originais. Para análise, as médias de oviposição foram transformadas em $\log \left(\mathrm{n}^{\circ}\right.$ de ovos $\left./ 10 \mathrm{~cm}^{2}+1\right)$. 
Oito sementes de cada genótipo foram semeadas, e no décimo segundo dia após o plantio, realizou-se o desbaste mantendo-se apenas duas plantas por vaso. Quando as plantas estavam com o segundo par de folhas completamente desenvolvidas, realizou-se infestação artificial mediante colocação de vasos com plantas de batata intensamente infestadas por adultos de $B$. tabaci biótipo B, entre os vasos de meloeiro, de forma equidistante. Esse procedimento foi adaptado daquele adotado por VALLE e LOURENÇão (2002), para avaliação de atratividade para adultos e de preferência para oviposição de $B$. tabaci biótipo B em genótipos de soja. A contagem dos adultos presentes na face abaxial de duas folhas, uma de cada planta pertencente à parcela, foi realizada em quatro épocas: 24, 48, 72 e 96 horas após a infestação. Com auxílio de um espelho, a fim de não tocar na folha e assim não perturbar os insetos, os adultos eram contados sempre no início da manhã.

No quarto dia, após a realização da última contagem de adultos, essas folhas foram destacadas para avaliação da oviposição. A fim de preservar a qualidade desse material, as folhas foram acondicionadas em saco plástico e guardadas em geladeira, para posterior manuseio. Com auxílio de estereoscópio, foi realizada a contagem do número de ovos presentes na face abaxial total das folhas, sob aumento de 16X. Para medição da área foliar, as folhas destacadas foram reproduzidas em papel vegetal e passadas através de medidor de área foliar, LI-COR (LI-3100A), para obtenção do número de adultos e ovos por $10 \mathrm{~cm}^{2}$.

O delineamento experimental foi o de blocos casualizados, composto por trinta e dois tratamentos (cultivares) repetidos seis vezes, totalizando 192 parcelas. Cada parcela foi constituída de um vaso contendo duas plantas. O valor referente a cada parcela foi obtido pela média da contagem de um par de folhas. Foram analisados os resultados das quatro avaliações de adultos e da de ovos, verificando-se a normalidade e aplicando-se o teste de homocedasticidade. Detectouse a necessidade de transformação dos dados por log $\left(\mathrm{n} .^{\circ}\right.$ de ovos $\left./ 10 \mathrm{~cm}^{2}+1\right)$, realizando-se a seguir a análise de variância, sendo as médias comparadas pelo teste de Tukey $(p<0,05)$

\section{Preferência para oviposição de B. tabaci biótipo B em teste sem chance de escolha}

Para determinar se a menor preferência para oviposição observada em teste de livre escolha era estável, foi realizado um teste em que o inseto não tinha possibilidade de escolha entre as cultivares para depositar seus ovos. Nesse experimento, foi avaliada a preferência para oviposição nas cinco cultivares com as menores médias de ovos $/ 10 \mathrm{~cm}^{2}$ ('Neve, 'Deneb', 'Vereda', 'Sweet Market' e 'Jangada') e nas duas mais suscetíveis ('Nilo' e 'Imperial'), em um total de sete tratamentos, selecionados do ensaio anterior de preferência para oviposição e atratividade. Utilizouse um vaso com duas plantas, avaliando-se uma folha por planta, obtendo-se a média de duas folhas por parcela.

Para este ensaio, foram utilizados vasos plásticos de 6,5 litros, sendo adotados para cultivo das plantas os mesmos procedimentos descritos no teste anterior. Quando as plantas estavam com três folhas completamente desenvolvidas, realizou-se a infestação artificial, colocando-se aproximadamente 150 adultos da mosca-branca, de idade desconhecida, por vaso, oriundos da criação-estoque. Para confinamento das moscas-brancas, foram utilizadas gaiolas com armação de ferro, cobertas com tecido de 'voil' e fechadas na altura mediana do vaso com barbante de algodão. As gaiolas e o método de infestação estão descritos em LOURENÇão (1980). Após uma semana, foi avaliada a oviposição em duas folhas por parcela, considerando-se os procedimentos descritos no teste anterior com chance de escolha.

O delineamento utilizado foi o de blocos casualizados, com sete tratamentos (cultivares) e dez repetições, totalizando 70 parcelas. Para fins de análise de variância, os dados foram transformados em $\log (\mathrm{x})$ e as médias comparadas pelo teste de Tukey $(p<0,05)$.

\section{Desenvolvimento de ovo a adulto de B. tabaci biótipo B}

Realizou-se o experimento a fim de verificar a possível ocorrência de antibiose entre as cultivares com menor atratividade para adultos e menor oviposição. Determinou-se o número de dias necessários para o desenvolvimento de $B$. tabaci biótipo B de ovo a adulto e a porcentagem de emergência de adultos dessa moscabranca em cada cultivar. Foi utilizado como padrão de suscetibilidade 'Nilo' e como padrão de resistência a cultivar Neve. As demais cultivares foram as mesmas do ensaio de preferência para oviposição sem chance de escolha: 'Jangada', 'Sweet Market', 'Vereda', 'Jangada' e 'Deneb'.

Para cada cultivar, foram utilizados cinco vasos de plástico com capacidade de três litros, preenchidos com terra misturada com composto orgânico e areia conforme procedimentos anteriores. Após a emergência, foi realizado desbaste, deixandose uma planta por vaso, mantido em prato plástico com água. Quando as plantas atingiram o estádio de dois pares de folha definitiva, os vasos foram colocados na criação de $B$. tabaci biótipo B por um 
período de três horas. Após esse período, cada planta foi levada ao laboratório onde, com o auxílio de estereoscópio, foi demarcada com caneta vermelha de retroprojetor de ponta fina, uma área com 45 ovos. Este procedimento foi adotado em cada planta das 35 parcelas.

Diariamente, durante 34 dias, foram inspecionadas as áreas demarcadas de cada planta, anotando-se o número de ovos, número de ninfas e o número de pupários vazios, indicando a emergência dos adultos. Com base nesses dados, foi determinado o número médio de dias necessários para o completo desenvolvimento de ovo-adulto e a porcentagem de emergência de adultos entre as cultivares.

O delineamento experimental foi de blocos casualizados, composto por sete tratamentos, repetidos cinco vezes. Para fins de análise, os valores de porcentagem média de emergência de adultos e os referentes ao número médio de dias necessários ao completo desenvolvimento foram analisados sem transformação. Efetuou-se análise de variância, sendo as médias comparadas pelo teste de Tukey $(p<0,05)$.

\section{Colonização de B.tabaci biótipo B}

Vinte dias após o término da avaliação de preferência no teste sem chance de escolha, época em que a maioria das plantas estava no processo de frutificação, estimou-se a colonização da moscabranca. Para isso, foi utilizada uma escala de notas (Figura 1), variando de 1 a 7 , sendo $1=$ folha sem infestação; 2 = folha com poucas ninfas;...; $76=$ folha totalmente colonizada por ninfas. Este método foi o mesmo adotado por VALLE (2001), em avaliação de graus de colonização de $B$. tabaci biótipo B em soja. A nota final da parcela resultou da média de notas de duas folhas por vaso, observando sempre folhas totalmente desenvolvidas do terço médio da planta.

O delineamento empregado foi de blocos casualizados, composto por sete tratamentos e dez repetições, totalizando 70 parcelas. Cada parcela foi constituída por um vaso com duas plantas. Para fins de análise estatística, as médias de colonização obtidas foram utilizadas sem tranformação Efetuouse análise de variância, sendo as médias comparadas pelo teste de Tukey $(p<0,05)$.

\section{Densidade de tricomas}

Para esta avaliação, envolvendo as sete cultivares dos testes sem chance de escolha, de colonização e do ciclo ovo-adulto, foram usadas folhas do estrato médio das plantas, nos estágios de desenvolvimento nos quais foram feitas as avaliações no teste de preferência para oviposição e de atratividade para adultos, com livre chance de escolha. A densidade foi medida na face abaxial das folhas pela contagem dos tricomas presentes em uma área da região central, por meio de um "vasador" de $6 \mathrm{~mm}$ de diâmetro $\left(28 \mathrm{~mm}^{2}\right)$. A avaliação foi feita com auxílio de estereoscópio, sob aumento de 16X. Utilizaram-se folhas desenvolvidas do terço superior das plantas, coletando-se quatro folhas por parcela, sendo totalizadas 24 áreas de $28 \mathrm{~mm}^{2}$ para cada cultivar. O delineamento foi inteiramente casualizado, com sete tratamentos e seis repetições, totalizando 42 parcelas, em um total de 168 folhas analisadas.

Para análise, os valores médios do número de tricomas foram analisados sem transformação. Efetuou-se análise de variância, sendo as médias comparadas pelo teste de Tukey $(p<0,05)$.

\section{Análise colorimétrica}

A fim de verificar possíveis efeitos da superfície das folhas dos diferentes genótipos de meloeiro sobre a mosca-branca, avaliaram-se as colorações das folhas, sendo a medição realizada mediante uso do colorímetro Minolta Color Reader CR10, com leitura em sistema CIE $\left({ }^{*} \mathrm{~L},{ }^{*} \mathrm{a},{ }^{*} \mathrm{~b}\right)$. Através do sensor do colorímetro é quantificada a energia refletida na região do espectro visível, resultante da interação da luz com a superfície da folha, utilizandose valores triestímulos básicos propostos pela CIE (Commision Internationale L'Eclarirage). O sistema CIE L*a*b* estabelece coordenadas uniformes no espaço tridimensional de cor, sendo " $L "$ a luminosidade e " $a$ " e " $b$ " contêm as informações de croma, onde "a" corresponde a um eixo que varia do vermelho ao verde e " $b$ " é um eixo que varia do amarelo ao azul (MinOLTA, 1998).

$\mathrm{O}$ ensaio foi delineado com os mesmos sete tratamentos dos experimentos anteriores, com dez repetições. Avaliou-se a região central da folha na face abaxial, tomando-se uma folha do segundo par de folhas totalmente desenvolvidas, sendo esta folha considerada uma parcela.

Para análise, os valores foram analisados sem transformação. Efetuou-se análise de variância, sendo as médias comparadas pelo teste de Tukey $(P<0,05)$.

\section{RESULTADOS E DISCUSSÃO}

Atratividade para adultos e preferência para oviposição de B. tabaci biótipo B em teste com chance de escolha 

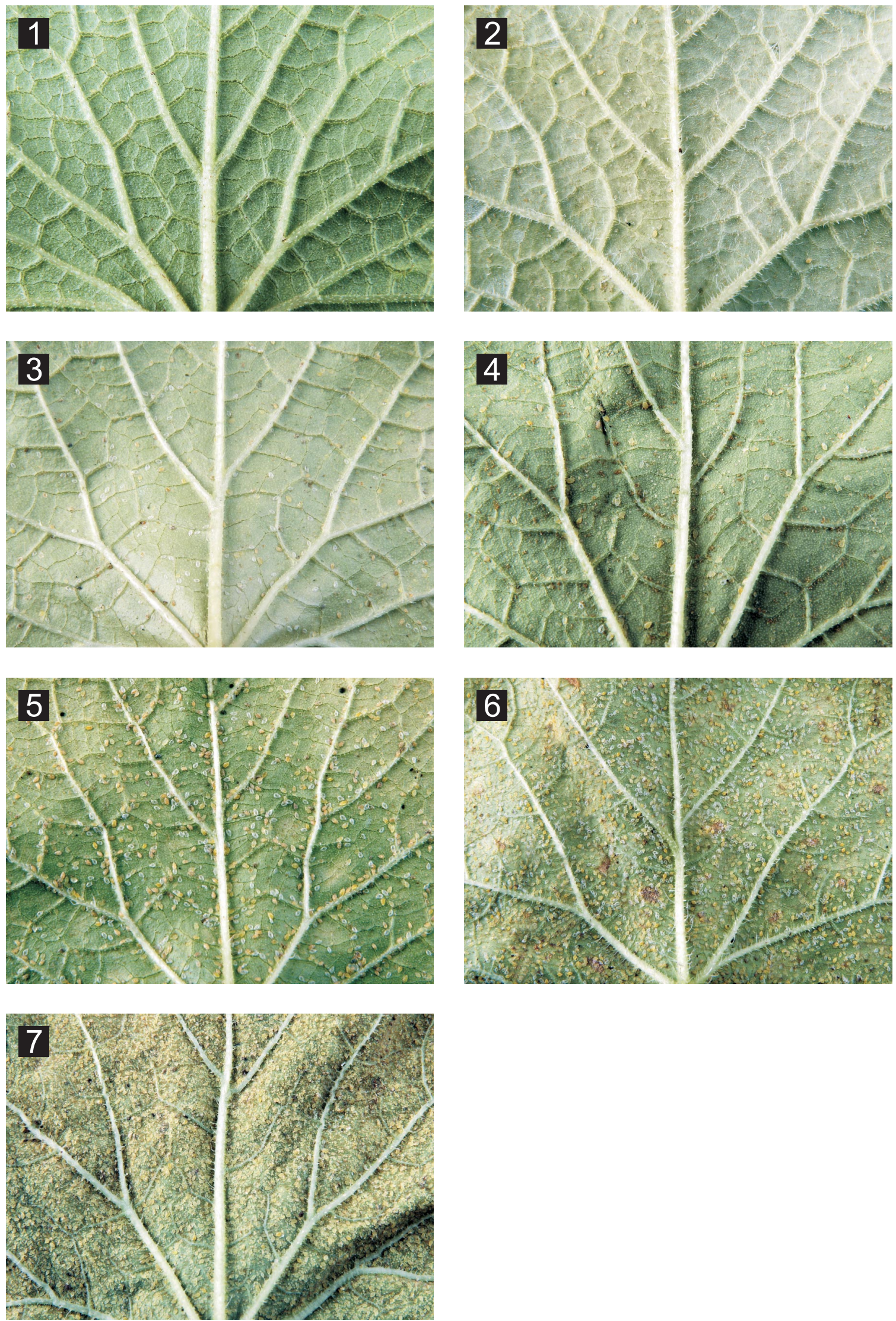

Figura 1. Escala de notas de colonização de folhas de meloeiro por B. tabaci biótipo B, variando de 1 a 7 . [1 = folhas sem infestação; 2 = folhas com poucos ovos e ninfas...; 7 = folhas totalmente infestadas por ovos e ninfas] 
'Neve' se destacou como a menos atrativa dentre as cultivares testadas, obtendo-se, na média das quatro avaliações $(24,48,72$ e 96 horas), o valor de 0,6 adulto $/ 10 \mathrm{~cm}^{2}$, enquanto a mais atrativa foi 'Nilo', com média de 5,6 adultos $/ 10 \mathrm{~cm}^{2}$, ficando as demais cultivares com valores intermediários para esse parâmetro (Tabela 1). CesAr et al. (2004a), avaliando a atratividade de adultos de $B$. tabaci biótipo $B$ em 15 cultivares de meloeiro, verificaram que 'AF646', 'Frevo' e 'Sweet Market' foram as mais atrativas $(126,31 ; 124,68$ e 114,06 adultos/folha, respectivamente), enquanto em 'Caipira', 'Gaúcho Redondo', 'Casca de Carvalho' e 'Neve' houve menor atratividade, com destaque para 'Neve', com 32,27 adultos/folha. Esse resultado ratifica os dados obtidos no presente estudo, em que 'Neve' também se destacou dos demais tratamentos como o menos atrativo.

A ocorrência de diferentes níveis de atratividade a adultos de $B$. tabaci biótipo $B$ em função do genótipo é conhecida também para outras espécies vegetais de expressão econômica. Em soja, avaliandose 20 genótipos abrangendo cultivares e linhagens, VALLE E LOURENÇão (2002) detectaram gradiente nesse germoplasma em relação à atratividade para adultos, constatando, dentre os menos atrativos, cultivares como IAC 17 e IAC 19. Em tomateiro, FANCELLI et al. (2003) verificaram, além de diferenças na atratividade, ausência de infestação de adultos em acessos de $L$. pennellii e L. hirsutum, espécies silvestres de Lycopersicon.

$\mathrm{Na}$ avaliação de oviposição, verificou-se extenso gradiente entre as cultivares, variando de 8,5 ('Neve') a 271,5 ovos $/ 10 \mathrm{~cm}^{2}$ ('Nilo'), material em que o inseto demonstrou marcante preferência para oviposição (Tabela 1). Caracterizando-se também como cultivar com alta média de oviposição, situa-se Imperial, com 216,8 ovos $/ 10 \mathrm{~cm}^{2}$, diferindo da menos ovipositada, que foi 'Neve' $(8,5)$. Este resultado foi semelhante ao obtido por CESAR et al. (2004b), em experimentos com diferentes cultivares de meloeiro em teste com chance de escolha, em que 'Neve' foi a menos ovipositada, com média de 3,9 ovos $/ \mathrm{cm}^{2}$, destacandose também entre as demais cultivares testadas.

Ocorrência de diferentes níveis de preferência para oviposição de $B$. tabaci biótipo B em função do genótipo também tem sido relatada para outras espécies vegetais de interesse econômico. Em aboboreiras, avaliando 16 cultivares de hábitos de crescimento de moita e rasteiro, Alves et al. (2005) detectaram gradiente de postura, destacando-se, entre os menos atrativos, as cultivares Novita e Atlas.

Em algodoeiro, em teste de preferência para oviposição por B. tabaci biótipo B com chance de escolha, TORREs et al. (2007) constataram menores oviposições nas cultivares BRS Aroeira, BRS Verde e BRS Ita 90-2, com médias de 7,9, 10,9 e 29 ovos $/ 4 \mathrm{~cm}^{2}$ respectivamente. As demais cultivares foram as mais preferidas, proporcionando 42 a 69,7 ovos $/ 4 \mathrm{~cm}^{2}$.

\section{Preferência para oviposição de B. tabaci biótipo B em teste sem chance de escolha}

Nesta avaliação, destacou-se como menos ovipositada a cultivar Neve, com 55,8 ovos $/ 10 \mathrm{~cm}^{2}$, diferindo de 'Jangada' $(122,0)$ e 'Nilo' $(118,0)$, as mais preferidas (Tabela 2). Com estes resultados observase que a menor oviposição de B. tabaci biótipo B ocorreu em 'Neve' em condições de livre escolha, e se mantém mesmo quando o inseto não tem chance de escolher, caracterizando-se, assim, como uma resistência estável.

Tabela 2. Médias ( \pm EP) de oviposição em teste sem chance de escolha, de desenvolvimento de ovo a adulto e de emergência de adultos de $B$. tabaci biótipo B, em sete cultivares de meloeiro, em casa de vegetação. Campinas, SP, $2007 / 2008$

\begin{tabular}{lccc}
\hline Cultivar & $\begin{array}{c}\text { Ovos } 10 \mathrm{~cm}^{-2}(*, * *) \\
(\text { dezembro de 2007) }\end{array}$ & $\begin{array}{c}\text { Duração de ovo a adulto } \\
\text { (janeiro de 2008) }\end{array}$ & $\begin{array}{c}\text { Emergência de adultos } \\
\text { (janeiro de 2008) }\end{array}$ \\
\hline Jangada & Número & dias & $\%$ \\
Nilo & $122,0 \pm 1,99 \mathrm{a}$ & $25,4 \pm 0,35 \mathrm{a}$ & $80,3 \pm 3,39 \mathrm{ab}$ \\
Imperial & $118,0 \pm 2,11 \mathrm{a}$ & $24,9 \pm 0,98 \mathrm{a}$ & $69,3 \pm 4,21 \mathrm{~b}$ \\
Deneb & $109,0 \pm 1,47 \mathrm{ab}$ & $24,9 \pm 0,22 \mathrm{a}$ & $90,9 \pm 2,06 \mathrm{a}$ \\
Sweet Market & $81,0 \pm 0,96 \mathrm{ab}$ & $24,7 \pm 0,39 \mathrm{a}$ & $89,6 \pm 3,39 \mathrm{a}$ \\
Vereda & $78,0 \pm 1,37 \mathrm{ab}$ & $24,3 \pm 0,43 \mathrm{a}$ & $77,8 \pm 2,83 \mathrm{ab}$ \\
Neve & $65,0 \pm 1,52 \mathrm{ab}$ & $24,9 \pm 0,16 \mathrm{a}$ & $68,2 \pm 2,56 \mathrm{~b}$ \\
CV $(\%)$ & $55,8 \pm 0,99 \mathrm{~b}$ & $24,0 \pm 0,43 \mathrm{a}$ & $80,5 \pm 3,62 \mathrm{ab}$ \\
\hline
\end{tabular}

* Médias seguidas pela mesma letra na coluna não diferem significativamente entre si pelo teste de Tukey $(p<0,05)$.

** Dados originais. Para análise, as médias foram transformadas em $\log (\mathrm{x})$. 
Há na literatura outros exemplos da manutenção da menor oviposição de B. tabaci biótipo B, em testes sem chance de escolha, com outras culturas. Em soja, confirmou-se nas cultivares IAC 17 e IAC 19 e na linhagem D 75-10169 a resistência do tipo nãopreferência para oviposição a B. tabaci biótipo B (VALLE e LOURENÇão, 2002), e em feijão, OrIANI e LARA (2000) verificaram o mesmo para os genótipos portadores de arcelina na semente.

\section{Desenvolvimento de ovo a adulto de B. tabaci biótipo B}

O período necessário para $B$. tabaci biótipo B completar o desenvolvimento de ovo a adulto teve pequena variação entre as cultivares, de 24,0 dias em Neve a 25,4 dias em Jangada, não sendo detectadas diferenças entre as cultivares avaliadas (Tabela 2). De acordo com a análise, o desenvolvimento de $B$. tabaci biótipo B ocorreu de forma semelhante em todos os tratamentos. É interessante mencionar que, em condições de casa de vegetação, sob temperatura de $25 \pm 8{ }^{\circ} \mathrm{C}$ e umidade relativa de $60 \pm 10{ }^{\circ} \mathrm{C}$, o ciclo de ovo a adulto de $B$. tabaci biótipo B em outra cucurbitácea, a abobrinha de crescimento tipo moita 'Caserta', variou de 25,0 a 28,3 dias (Villas BôAs et al., 2002), resultado muito próximo ao alcançado neste trabalho (Tabela 2).

Quanto à emergência de adultos, 'Vereda' e 'Nilo' induziram as mais baixas médias, respectivamente, de $68,2 \%$ e $69,3 \%$. Alterações no ciclo de vida em função do genótipo em que o inseto está se criando, como alongamento do ciclo e redução de emergência de adultos, são considerados indicativos da presença de antibiose (LARA, 1991). Assim, considerando-se os resultados de emergência de adultos nas sete cultivares, infere-se que 'Vereda' e 'Nilo' podem ser consideradas como cultivares menos favoráveis e portadoras de resistência moderada do tipo antibiose, pois reduziram a emergência de adultos. Em outro extremo, situam-se 'Imperial' $(90,9 \%)$ e 'Deneb' $(89,6 \%)$, cultivares mais adequadas ao desenvolvimento de $B$. tabaci biótipo B por viabilizar o maior número de adultos emergidos.

\section{Colonização de Bemisia tabaci biótipo B}

Foram detectados diferentes graus de colonização entre as cultivares (Tabela 3 ), evidenciando como a menos colonizada a cultivar Neve, com nota média 2,6. Esta cultivar já havia demonstrado comportamento de resistência quanto à preferência para oviposição e à atratividade para adultos. As cultivares Imperial, Jangada, Vereda e Deneb foram aquelas em que ocorreram maiores graus de colonização: 6,$2 ; 5,8$; 5,4 e 5,3 respectivamente, permanecendo a cultivar Sweet Market em nível intermediário. Deve ser ressaltado que a cultivar com a média mais alta, Imperial, situou-se no teste de preferência para oviposição sem chance de escolha e também na avaliação de emergência de adultos entre os mais suscetíveis, o que sugere que seja um genótipo bastante favorável ao inseto.

Tabela 3. Média $( \pm \mathrm{EP})$ da colonização de B. tabaci biótipo B e densidade de tricomas da superfície abaxial de folhas de sete cultivares de meloeiro. Campinas, SP, 2007

\begin{tabular}{lcr}
\hline Cultivar & Nota de colonização $\left.{ }^{* * *}\right)$ & Número de tricomas $/ 28 \mathrm{~mm}^{2}\left({ }^{* *}\right)$ \\
\hline Imperial & $6,2 \pm 0,11 \mathrm{a}$ & $622,7 \pm 5,40 \mathrm{a}$ \\
Jangada & $5,8 \pm 0,15 \mathrm{a}$ & $596,0 \pm 10,93 \mathrm{a}$ \\
Vereda & $5,4 \pm 0,31 \mathrm{a}$ & $605,3 \pm 9,55 \mathrm{a}$ \\
Deneb & $5,3 \pm 0,41 \mathrm{a}$ & $297,7 \pm 4,17 \mathrm{~d}$ \\
Nilo & $5,0 \pm 0,34 \mathrm{ab}$ & $538,6 \pm 11,69 \mathrm{~b}$ \\
Sweet Market & $3,9 \pm 0,41 \mathrm{~b}$ & $528,2 \pm 9,39 \mathrm{~b}$ \\
Neve & $2,6 \pm 0,31 \mathrm{c}$ & $345,0 \pm 9,89 \mathrm{c}$ \\
\hline CV $(\%)$ & 20,04 & 4,41 \\
\hline
\end{tabular}

$\left({ }^{*}\right)$ Escala de notas: nota $1=$ folha sem infestação; nota $2=$ folha com poucas ninfas; ;.; nota 7 = folha totalmente colonizada por ninfas (Figura 1).

$(* *)$ Médias seguidas pela mesma letra na coluna não diferem significativamente entre si pelo teste de Tukey $(p<0,05)$. 


\section{Densidade de tricomas}

As cultivares com folhas com a mais alta pilosidade em sua face inferior foram Imperial, Vereda e Jangada, com $622,7,605,3$ e 596,0 tricomas $/ 28 \mathrm{~mm}^{2}$ respectivamente (Tabela 3 ). As cultivares menos pilosas foram Deneb $(297,7)$ e Neve $(345,0$ tricomas / $28 \mathrm{~mm} 2$ ). BUTLER JR. et al. (1986) verificaram, em plantas de algodão com folhas pilosas, mais ovos e adultos do que em plantas semi-glabras e glabras, fato esse também apontado por Mound (1965), estudando $B$. tabaci em folhas pilosas de algodoeiro em relação às glabras. Esse efeito dos tricomas sobre B. tabaci pode também ser comprovado no presente estudo, em que as cultivares mais atrativas para adultos e mais preferidas para oviposição ('Nilo' e 'Imperial'), ambas com chance de escolha, caracterizam-se pela alta pilosidade. O oposto ocorre com a cultivar Neve, nãopreferida para oviposição, não atrativa para os adultos e com baixo grau de colonização.

Heinz e Zalom (1995) sugerem que o tipo, o comprimento e o arranjo espacial dos tricomas foliares parecem ter influência na densidade populacional de mosca-branca em diferentes culturas. Esses autores também relatam que o comportamento preferencial de moscas-brancas para oviposição próxima aos tricomas é devido à pressão de seleção exercida pelos inimigos naturais. CHU et al. (1995) acrescentam ainda que esse comportamento é influenciado pelo microhabitat melhorado, proporcionado pelas folhas pilosas, que podem interferir no movimento do ar que circula na superfície abaxial da folha.

No teste de preferência sem chance de escolha não foi possível obter qualquer relação entre o número de tricomas e a oviposição, o que está de acordo com McAuslane (1996), que afirmou que em testes sem chance de escolha, o efeito da densidade de tricomas na preferência para oviposição é menos evidente, o que impossibilita a detecção da preferência entre os genótipos. Da mesma forma, MEAGHER Jr. et al. (1997), trabalhando com cultivares de algodoeiro, também não conseguiram relacionar a densidade de tricomas com o número de ovos nesse tipo de teste, fato corroborado neste trabalho.

Lima e LARA (2004) observaram em soja, em ensaio com chance de escolha, que a linhagem PI 227687, com a maior quantidade de tricomas, foi o genótipo mais ovipositado, enquanto 'BR-82 $12547^{\prime}$ e PI 229358 , com as menores quantidades de tricomas, foram os menos ovipositados por $B$. tabaci biótipo B.

Tabela 4. Avaliação colorimétrica da região inferior da folha, em sete cultivares de meloeiro, em casa de vegetação. Sistema CIE (L,a,b). Campinas, SP, 2007

\begin{tabular}{lccr}
\hline Cultivar & $\mathrm{L}\left(^{*}\right)$ & $\mathrm{a}\left(^{*}\right)$ & $\mathrm{b}\left(^{*}\right)$ \\
\hline 'Imperial' & $46,2 \pm 0,52 \mathrm{ab}$ & $-11,5 \pm 0,18 \mathrm{~b}$ & $20,6 \pm 0,69 \mathrm{ab}$ \\
'Jangada' & $47,3 \pm 2,19 \mathrm{ab}$ & $-11,7 \pm 0,18 \mathrm{~b}$ & $21,2 \pm 1,04 \mathrm{ab}$ \\
'Vereda' & $48,2 \pm 0,71 \mathrm{a}$ & $-12,4 \pm 0,17 \mathrm{bc}$ & $23,6 \pm 0,97 \mathrm{a}$ \\
'Deneb' & $47,0 \pm 0,43 \mathrm{ab}$ & $-12,8 \pm 0,23 \mathrm{c}$ & $23,1 \pm 0,81 \mathrm{a}$ \\
'Nilo' & $47,3 \pm 1,51 \mathrm{ab}$ & $-11,8 \pm 0,25 \mathrm{~b}$ & $23,2 \pm 1,23 \mathrm{a}$ \\
'Sweet M.' & $46,6 \pm 0,53 \mathrm{ab}$ & $-11,5 \pm 0,21 \mathrm{~b}$ & $19,7 \pm 0,78 \mathrm{ab}$ \\
'Neve' & $45,2 \pm 0,50 \mathrm{~b}$ & $-10,6 \pm 0,19 \mathrm{a}$ & $17,4 \pm 0,82 \mathrm{~b}$ \\
\hline CV (\%) & 4,23 & 23,87 & 13,67 \\
\hline
\end{tabular}

(*) Médias seguidas pela mesma letra na coluna não diferem significativamente entre si pelo teste de Tukey $(p<0,05)$.

\section{Análise colorimétrica}

$\mathrm{Na}$ escala $\mathrm{L}$, que corresponde à intensidade de claridade refletida pela folha, observa-se que 'Vereda' $(48,2)$ diferiu da cultivar Neve, menos clara $(45,2)$ (Tabela 4). Os demais tratamentos ficaram em posição intermediária. Já para a leitura de a, que corresponde à quantidade de verde presente nas folhas, nota-se que em'Deneb' $(-12,8)$ houve intensidade moderada dessa coloração, juntamente com 'Vereda' $(-12,4)$, a qual não diferiu das demais cultivares, à exceção de 'Neve', com verde mais intenso $(-10,6)$, que diferiu de todas as cultivares testadas. Na análise da coloração amarela, descrita pela escala b, novamente 'Neve' $(17,4)$ contrastou com as cultivares Deneb, Nilo e Vereda $(23,1 ; 23,2$ e 23,6 respectivamente). 
A cor é o fator mais importante para a seleção do hospedeiro à distância por moscas-brancas, cujo mecanismo de percepção permite a distinção até mesmo de matizes semelhantes à folhagem das plantas (Lenteren e Noldus, 1990). Considerando-se os resultados colorimétricos do presente estudo, pode-se supor que a coloração das folhas dos genótipos de meloeiro esteja afetando B. tabaci biótipo B, tanto na atratividade, como fator físico, como também associada a algum fator químico, influindo no desenvolvimento do inseto, conforme observado nos testes de desenvolvimento do inseto e na colonização das plantas.

Considerando-se todas as avaliações de resistência, ou seja, a atratividade para adultos, a preferência para oviposição e a colonização, 'Neve' foi a cultivar mais resistente a $B$. tabaci biótipo $B$, podendo ser recomendada para plantio em regiões onde essa moscabranca ocorra de forma acentuada, bem como para uso em programas de melhoramento em que se objetive a obtenção de cultivares com resistência a insetos.

\section{CONCLUSÕES}

1. Neve é a cultivar menos atrativa e Nilo, a mais atrativa a adultos de $B$. tabaci biótipo $B$.

2. Neve é a cultivar menos preferida para oviposição, em testes com e sem chance de escolha.

3. Não há diferença no tempo de desenvolvimento ovo-adulto entre as cultivares avaliadas, porém a emergência de adultos é afetada, com 'Vereda' e 'Nilo' proporcionando menor emergência.

4. Deneb e Neve são as cultivares com menor média de tricomas por área, enquanto 'Vereda', 'Jangada' e 'Vereda' se destacam pela presença de alta pilosidade, com as maiores médias observadas;

5. A maior intensidade de verde na folha ocorre na cultivar Neve.

\section{AGRADECIMENTOS}

À FAPESP, pela concessão de bolsa de mestrado para o primeiro autor, e ao $\mathrm{CNPq}$, pela concessão de bolsa de produtividade em pesquisa para o segundo autor.

\section{REFERÊNCIAS}

ALVES, A.C.; LOURENÇÃO, A.L.; MELO, A.M.T. Resistência de genótipos de aboboreira a Bemisia tabaci (Genn.) biótipo B (Hemiptera: Aleyrodidade). Neotropical Entomology, v.34, p.973-979, 2005.
AZEVEDO, F.R.; BLEICHER, E. Distribuição vertical e setorial das ninfas de mosca-branca nas folhas do meloeiro. Horticultura Brasileira, v.21, p.464-467, 2003.

BROWN, J.K.; FROHLICH, D.R.; ROSELL, R.C. The sweetpotato or silverleaf whiteflies: biotypes of Bemisia tabaci or a species complex? Annual Review of Entomology, v.40, p. 511-534, 1995.

BUTLER JR., G.D.; HENNEBERRY, T.J.; WILSON, F.D. Bemisia tabaci (Homoptera: Aleyrodidae) on cotton: adult activity and cultivar oviposition preference. Journal of Economic Entomology, v.79, p.350-354, 1986.

CESAR, A.P.; LIMA, L.C.; CAMPOS, A.R. Atratividade de cultivares de meloeiro à mosca branca Bemisia tabaci (Hemiptera: Aleyrodidae) biótipo B. In: CONGRESSO BRASILEIRO DE ENTOMOLOGIA, 20., 2004, Gramado. Resumos... Gramado: Sociedade Entomológica do Brasil, 2004a. p.590.

CESAR, A.P.; LIMA, L.C.; CAMPOS, A.R. Preferência da mosca branca Bemisia tabaci (Hemiptera: Aleyrodidae) biótipo B para oviposição em plantas de meloeiro, com chance de escolha. In: CONGRESSO BRASILEIRO DE ENTOMOLOGIA, 20., 2004, Gramado. Resumos... Gramado: Sociedade Entomológica do Brasil, 2004b.p.590.

CHU, C.C.; HENNEBERRY, T.J.; COHEN, A.C. Bemisia argentifolii (Homoptera: Aleyrodidae) on cotton: host preference and factors affecting oviposition and feeding site preference. Annals of Entomological Society of America, v.94, p.354-360, 1995.

DENHOLM, I.; CAHILL, M.; BYRNE, F.J.; DEVONSHIRE, A.L. Progress with documenting and combating insecticide resistance in Bemisia. In: GERLING, D., MAYER R.T. (Ed.). Bemisia 1995: taxonomy, biology, damage, control and management. Andover, UK: Intercept, 1996. p.577-603.

FANCELLI, M.; VENDRAMIM, J.D.; LOURENÇÃO, A.L.; DIAS, C.T.S. Atratividade e preferência para oviposição de Bemisia tabaci (Gennadius) (Hemiptera: Aleyrodidae) biótipo B em genótipos de tomateiro. Neotropical Entomology, v.32, p.319328, 2003.

FERNANDES, O.A.; FERREIRA, C.C.; MONTAGNA, M.A. Manejo integrado de pragas do melão: manual de reconhecimento das pragas e táticas de controle. Jaboticabal: Funep, 2000. 28p.

HEINZ, K.M.; ZALOM, F.G. Variation in trichome-based resistance to Bemisia argentifolii (Homoptera: Aleyrodidae) oviposition on tomato. Journal of Economic Entomology, v.88, p.1494-1502, 1995.

HOROWITZ, A.R.; ISHAAYA, I. Chemical control of Bemisia, management and application. In: GERLING, D., MAYER, R.T. (Ed.). Bemisia 1995: taxonomy, biology, damage, control and management. Andover, UK: Intercept, 1996. p.537-556.

LARA, F.M. Princípios de resistência de plantas a insetos. 2.ed. São Paulo: Ícone, 1991. 336p. 
LENTEREN, J.C. VAN; NOLDUS, L.P.J.J. Whitefly - plant relationships: behavioral and ecological aspects. In: GERLING, D. (Ed.). Whiteflies: their bionomics, pest status and management. Andover, UK: Intercept, 1990. p.47-89.

LIMA, A.C.S.; LARA, F.M. Resistência de genótipos de soja à mosca-branca Bemisia tabaci biótipo B (Hemiptera: Aleyrodidae). Neotropical Entomology, v.33, p.71-75, 2004.

LOURENÇÃO, A. L. Bemisia tabaci (Gennadius, 1889) (Homoptera: Aleyrodidae) em soja (Glycine max (L.) Merrill): influência da variedade, da idade da planta e de cruzamentos intervarietais sobre a oviposição e desenvolvimento do inseto. 1980.58p. Dissertação (Mestrado) - Escola Superior de Agricultura "Luiz de Queiroz", Universidade de São Paulo, Piracicaba.

MAPA (MINISTÉRIO DA AGRICULTURA, PECUÁRIA E ABASTECIMENTO. - AGÊNCIA BRASIL - Radiobrás 4 de Fevereiro de 2008 - 20h32 http:/ / www.agenciabrasil.gov.br/ noticias/2008/02/04/materia.2008-02-04.4489290659/view

MCAUSLANE, H.J. Influence of leaf pubescence on ovipositional preference of Bemisia argentifolii (Homoptera: Aleyrodidae) on soybean. Environmental Entomology, v.25, p.834-841, 1996.

MEAGHER JR, R.L.; SMITH, C.W.; SMITH, W.J. Preference of Gossypium genotypes to Bemisia argentifolii (Homoptera: Aleyrodidae). Journal of Economic Entomology, v.90, p.10461052, 1997.

MINOLTA. Precise color communication: color control from perception to instrumentation. Japan, 1998. 59p.

MOUND, L.A. Effects of leaf hair on cotton whitefly populations in the Sudan Gezira. The Empire Cotton Growing Review, v.42, p.33-40, 1965.

ORIANI, M.A.; LARA, F.M. Oviposition preference of Bemisia tabaci (Genn.) biotype B (Homoptera: Aleyrodidae) for bean genotypes containing arcelin in the seeds. Anais da Sociedade Entomológica do Brasil, v.29,p.565-572, 2000.

RAIJ, B.; CANTARELLA, H.; QUAGGIO, J.A.; FURLANI, A.M.C. Recomendações de adubação e calagem para o Estado de São Paulo. Campinas. Instituto Agronômico - Fundação IAC, , 1997. p.285, (Boletim Técnico 100)

RILEY, D.G.; PALUMBO, J.C. Interaction of silverleaf (Homoptera: Aleyrodidae) with cantaloupe yield. Journal of Economic Entomology, v.88, p.1726-1732, 1995.

SIMMONS, A.M.; McCREIGHT, J.D. Evaluation of melon for resistance to Bemisia argentifolii (Homoptera: Aleyrodidae). Journal of Economic Entomology, v.89, p.1663-1668, 1996.

TORRES, L.C.; SOUZA, B.; AMARAL, B.B.; TANQUE, R.L. Biologia e não-preferência para oviposição por Bemisia tabaci (Gennadius) biótipo B (Hemiptera: Aleyrodidae) em cultivares de algodoeiro. Neotropical Entomology, v.36, p.445-453, 2007.

VALLE, G.E. Resistência de genótipos de soja a Bemisia tabaci biótipo B. 2001. 80p. Dissertação (Mestrado)- Instituto Agronômico, Campinas.
VALLE, G.E.; LOURENÇÃO, A.L. Resistência de genótipos de soja a Bemisia tabaci (Genn.) biótipo B (Hemiptera: Aleyrodidae). Neotropical Entomology, v.31, p.285-295, 2002.

VILLAS BÔAS, G.L.; BUSO, J.A.; VIEIRA, J.V. Avaliação de genótipos de melão para resistência à mosca branca. In: CONGRESSO BRASILEIRO DE ENTOMOLOGIA, 20., 2004, Gramado. Resumos... Gramado: Sociedade Entomológica do Brasil, 2004. p.578.

VILLAS BÔAS, G.L.; FRANÇA, F.H.; MACEDO, N. Potencial biótico da mosca-branca Bemisia argentifolii a diferentes plantas hospedeiras. Horticultura Brasileira, v.20, p.71-79, 2002. 